\title{
Prevalence, treatment, and control of dyslipidemia in diabetic participants of two brazilian cohorts: a place far from heaven
}

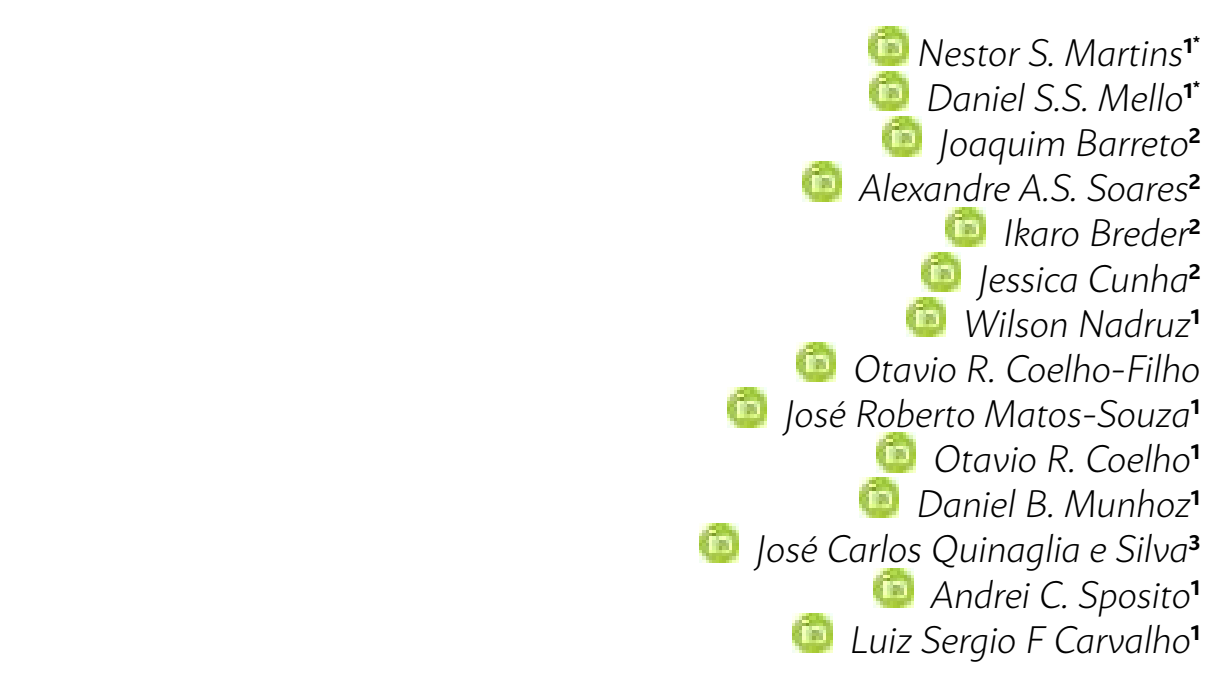

*The co-authors had an equal contribution for this present article.

1. Cardiology Department, Faculty of Medical Sciences, State University of Campinas (Unicamp), Campinas, SP, Brasil 2. Laboratory of Vascular Biology and Atherosclerosis (AteroLab) 3. School of Higher Education in Sciences and Health, Brasília, DF, Brasil

http://dx.doi.org/10.1590/1806-9282.65.1.3

\section{SUMMARY}

OBJECTIVE: Diabetes is one of the leading causes of cardiovascular mortality. Over the last years, mortality has decreased significantly, more in individuals with diabetes than in healthy ones. That is mostly due to the control of other cardiovascular risk factors. The objective of our study was to analyze the dyslipidemia control in two diabetes cohorts.

METHODS: Patients from two distinct cohorts were studied, 173 patients from the BHS (Brasilia Heart Study) and 222 patients from the BDS (Brazilian Diabetes Study). The data on dyslipidemia control were studied in both different populations. All patients had diabetes.

RESULTS: There are significant differences concerning comorbidities between the LDL-C and BDS groups. The average glycated hemoglobin is of 8.2 in the LDL-C > 100 group in comparison with 7.7 and 7.5 in the $70-100$ and $<70$ groups, respectively $(p=0.024)$. There is a higher percentage of hypertensive patients with LDL between 70-100 (63.9\%), when comparing the $<70$ and $>100$ groups (54.3\% and $54.9 \%$, respectively; $p=0.005$ ). Diastolic pressure is higher in the group with $L D L>100$, with an average of $87 \mathrm{mmHg}$, in comparison with $82.6 \mathrm{mmHg}$ and $81.9 \mathrm{mmHg}$ in the $70-100$ and $<70$ groups, respectively $(p=0.019)$. The group with LDL $>100$ has the greatest percentage of smokers (8.7\%) in comparison with the groups with LDL between $70-100$ and $<70(5.6 \%$ and $4.3 \%$, respectively; $p=$ 0.015). There is also a difference in the previous incidence of coronaropathy. In the group with $L D L<70,28.3 \%$ of patients had already experienced a previous infarction, compared with $11.1 \%$ and $10.6 \%$ in the $70-100$ and $>100$ groups, respectively $(p<0.001)$.

CONCLUSIONS: The data in our study have shown that the dyslipidemia control in diabetic patients is inadequate and there is a tendency of direct association between lack of blood glucose control and lack of dyslipidemia control, in addition to the association with other cardiovascular risk factors, such as diastolic hypertension and smoking. This worsened control might be related to the plateau in the descending curve of mortality, and investments in this regard can improve the cardiovascular health in diabetic patients.

KEYWORDS: Dyslipidemias. Diabetes mellitus. Risk factors. Targets.

DATE OF SUBMISSION: 16-Oct-2018

DATE OF ACCEPTANCE: 26-Oct-2018

CORRESPONDING AUTHOR: Luiz Sérgio F de Carvalho

Cardiology Department - Faculty of Medical Sciences - State University of Campinas (Unicamp)

Campinas, SP, Brasil - CEP 13084-971

E-mail: luizsergiofc@gmail.com 


\section{INTRODUCTION}

Diabetes is a huge cause of morbidity, mortality and economic impact. It affects 415 million individuals worldwide, with an increase in prevalence over the past years, going from $4.7 \%$ in 1980 to $8.5 \%$ in 2014, most significantly in countries with low and medium income ${ }^{2}$. In Brasil, the estimated prevalence is of $8.1 \%$. It is the direct cause of $6 \%$ of all deaths in the country, in addition to contributing to $31 \%$ of deaths attributed to cardiovascular disease ${ }^{3}$.

Over the last 30 years, cardiovascular mortality was substantially reduced, more so in diabetic individuals than in healthy ones, reaching a plateau after 2008-2010.4,5 In large part, this more favorable evolution of the cardiovascular prognosis in diabetic patients was due to an improved response to acute cardiovascular care in this population and also the

TABLE 1: CHARACTERISTICS OF PATIENTS ENROLLED IN THE BRAZILIAN DIABETES STUDY

\begin{tabular}{l|l|l|l|l}
\multicolumn{5}{|c}{ LDL-C, mg/dL } \\
\hline & $>100$ & $70-100$ & $<70$ & $p$ \\
\hline N (222) & $104(47 \%)$ & $72(32 \%)$ & $46(21 \%)$ & \\
\hline Demographics & & & & \\
\hline Age, years & $58.6 \pm 6.9$ & $59.8 \pm 7.1$ & $61.1 \pm 6.5$ & 0.106 \\
\hline Schooling, years & $10.8 \pm 4.1$ & $10.61 \pm 4.7$ & $9.96 \pm 4.5$ & 0.538 \\
\hline Men, \% & 53.8 & 55.6 & 73.9 & 0.058 \\
\hline Medical history & & & & \\
\hline Previous AMI, \% & 10.6 & 11.1 & 28.3 & $<0.001$ \\
\hline $\begin{array}{l}\text { Smokers, \% / For- } \\
\text { mer smokers, \% }\end{array}$ & $8.7 / 31.7$ & $5.6 / 30.6$ & $4.3 / 28.3$ & $0.015 /$ \\
\hline Hypertension, \% & 54.8 & 63.9 & 54.3 & 0.011 \\
\hline Hemodynamics & & & & \\
\hline SBP, mmHg & $149.47 \pm 22.0$ & $143.75 \pm 20.4$ & $145.71 \pm 20.6$ & 0.177 \\
\hline SBP, mmHg & $87.09 \pm 13.2$ & $82.65 \pm 10.2$ & $81.9 \pm 12.8$ & 0.019 \\
\hline HR, bpm & $78.13 \pm 12.5$ & $75.01 \pm 11.53$ & $74.33 \pm 11.0$ & 0.114 \\
\hline ER, \% & $57.6 \pm 11.6$ & $60.6 \pm 9.1$ & $59.4 \pm 6.2$ & 0.782 \\
\hline Biochemistry & & & & \\
\hline Blood glucose, & $172.6 \pm 69.6$ & $163.8 \pm 58.4$ & $159.1 \pm 54.8$ & 0.439 \\
\hline mg/dL & & & & \\
\hline HbA1c, \% & $8.2 \pm 2.0$ & $7.7 \pm 1.4$ & $7.5 \pm 1.3$ & 0.024 \\
\hline Creatinine, mg/dL & $0.89 \pm 0.22$ & $0.88 \pm 0.18$ & $0.94 \pm 0.20$ & 0.316 \\
\hline HDL-C, mg/dL & $42.5 \pm 12.4$ & $44.2 \pm 13.4$ & $43.0 \pm 14.3$ & 0.681 \\
\hline LDL-C, mg/dL & $135.4 \pm 32.1$ & $88.1 \pm 8.0$ & $58.0 \pm 10.5$ & $<0.001$ \\
\hline TG, mg/dL & $234.5 \pm 138$ & $158.7 \pm 92.6$ & $153.7 \pm 156.5$ & $<0.001$ \\
\hline PCRus, mg/L & $0.42 \pm 0.54$ & $0.32 \pm 0.32$ & $0.35 \pm 0.41$ & 0.343 \\
\hline Treatment & & & & \\
\hline Simvastatin, \% & 21 & 38 & 53 & $<0.001$ \\
\hline & & & & \\
\hline
\end{tabular}

SBP: systolic blood pressure; DBP: diastolic blood pressure; HR: heart rate; HbA1C: glycated hemoglobin; TG: triglycerides; CRP: ultrasensitive C-reactive protein. improvement in the treatment of comorbidities such as hypertension and dyslipidemia.

The response to the lipid-lowering treatment has been widely demonstrated, and each reduction of 40 $\mathrm{mg} / \mathrm{dL}(1 \mathrm{mmol} / \mathrm{L})$ in LDL cholesterol translates into $20 \%$ less incidence of more serious cardiovascular events and $16 \%$ less cardiovascular mortality. ${ }^{6}$ Interestingly, in a subanalysis of the Improve-IT study, only diabetic patients benefited from the addition of ezetimibe on top of the maximum dose of statin. ${ }^{7}$

Despite the relevancy of the subject, adherence to the lipid-lowering treatment is probably the most significant barrier and must represent part of the explanation for the plateau in the curve of mortality trend over the last decade. However, data on the control of LDL cholesterol in Brasil are very scarce and inconsistent. The most relevant data available on the subject comes from the Elsa study (Longitudinal Study of Adult Health) and suggests that the adequate con-

TABLE 2: CHARACTERISTICS OF PATIENTS ENROLLED IN THE BRASÍLIA HEART STUDY

\begin{tabular}{|c|c|c|c|c|}
\hline \multicolumn{5}{|c|}{ LDL-C, mg/dL } \\
\hline & $>100$ & $70-100$ & $<70$ & p \\
\hline $\mathbf{N}(173)$ & $113(65 \%)$ & $37(21 \%)$ & $23(13 \%)$ & \\
\hline \multicolumn{5}{|l|}{ Demographics } \\
\hline Age, years & $62.24 \pm 9.9$ & $64.51 \pm 11.4$ & $61.48 \pm 10.8$ & 0.441 \\
\hline Schooling, years & $7.3 \pm 4$ & $7.2 \pm 5$ & $7.6 \pm 5$ & 0.944 \\
\hline Men, \% & 67.3 & 64.9 & 73.9 & 0.759 \\
\hline $\mathrm{BMI}, \mathrm{kg} / \mathrm{m}^{2}$ & $27.7 \pm 4$ & $28.2 \pm 6$ & $27.4 \pm 4$ & 0.726 \\
\hline \multicolumn{5}{|l|}{ Medical history } \\
\hline Previous AMI \% & $12.4 \%$ & $27.0 \%$ & $21.7 \%$ & 0.093 \\
\hline Smoker, \% & 69.9 & 67.6 & 69.6 & 0.964 \\
\hline Hypertension, \% & 29.2 & 18.9 & 30.4 & 0.442 \\
\hline \multicolumn{5}{|l|}{ Hemodynamics } \\
\hline $\mathrm{SBP}, \mathrm{mmHg}$ & $137 \pm 30$ & $141 \pm 36$ & $128 \pm 26$ & 0.317 \\
\hline $\mathrm{SBP}, \mathrm{mmHg}$ & $87 \pm 19$ & $86 \pm 20$ & $82 \pm 19$ & 0.579 \\
\hline $\mathrm{HR}, \mathrm{bpm}$ & $81 \pm 17$ & $80 \pm 16$ & $72 \pm 18$ & 0.099 \\
\hline \multicolumn{5}{|l|}{ Biochemistry } \\
\hline $\begin{array}{l}\text { Blood glucose, mg/ } \\
\mathrm{dL}\end{array}$ & $206 \pm 87$ & $200 \pm 84$ & $191 \pm 98$ & 0.741 \\
\hline $\mathrm{HbA1c}, \%$ & $8.1 \pm 2.3$ & $8.1 \pm 2.0$ & $8.1 \pm 1.9$ & 0.983 \\
\hline $\mathrm{Cr}, \mathrm{mg} / \mathrm{dL}$ & $1.16 \pm 0.35$ & $1.18 \pm 0.52$ & $1.15 \pm 0.71$ & 0.966 \\
\hline $\mathrm{HDL}-\mathrm{C}, \mathrm{mg} / \mathrm{dL}$ & $39.0 \pm 9.8$ & $37.0 \pm 10.4$ & $27.1 \pm 10.0$ & $<0.001$ \\
\hline $\mathrm{LDL}-\mathrm{C}, \mathrm{mg} / \mathrm{dL}$ & $140.7 \pm 34.9$ & $88.3 \pm 8.0$ & $56.7 \pm 13.8$ & $<0.001$ \\
\hline $\mathrm{TG}, \mathrm{mg} / \mathrm{dL}$ & $166.7 \pm 73.2$ & $142.2 \pm 90.8$ & $175.4 \pm 130.1$ & 0.247 \\
\hline PCRus, mg/L & $1.39 \pm 2.25$ & $2.45 \pm 4.04$ & $2.26 \pm 4.20$ & 0.120 \\
\hline \multicolumn{5}{|l|}{ Treatment } \\
\hline Simvastatin, \% & 28.8 & 27.8 & 30.4 & 0.976 \\
\hline
\end{tabular}

SBP: systolic blood pressure; DBP: diastolic blood pressure; HR: heart rate; HbA1C: glycated hemoglobin; TG: triglycerides; CRP: ultrasensitive C-reactive protein. 
trol of dyslipidemia in the general population is lower than $10 \%{ }^{8}$ However, it is well known that the Elsa population had an educational background different from that of most of the Brazilian population (52.6\% with complete higher education). In the diabetic population, data are even more scarce, which has limited the development of public policies that address this group of patients.

The purpose of this study is to analyze data concerning the dyslipidemia control in diabetic patients using the population from two Brazilian cohorts.

\section{METHOD}

The population of this study is composed of individuals from two distinct cohorts, with 173 patients from the BHS (Brasília Heart Study) and 222 patients from the BDS (Brazilian Diabetes Study). There were no patients who participated in both cohorts.

\section{Brasília Heart Study}

The patients included in the BHS were consecutively enrolled provided they presented a diagnosis of infarction with ST-segment elevation admitted within 24 hours of the onset of pain at the Basic Hospital of the Federal District, the largest public hospital of the Federal Capital. A total of 173 patients admitted between 2006 and 2017 were included in the analysis. The inclusion criteria were: (i) less than 24 hours from the onset of the AMI symptoms; (ii) ST-segment elevation of at least $1 \mathrm{~mm}$ (frontal plane) or $2 \mathrm{~mm}$ (horizontal plane) in two contiguous leads; (iii) evidence of myocardial necrosis due to the rise in CK-MB and troponin; (iv) glycated hemoglobin $>6.5 \%$ or a previous diagnosis of diabetes with use of anti-diabetic medication; (v) absence of cognitive incompetence that prevents the verbal response to medical questionnaires or the return to medical consultations. During the evaluation, will be carried out: (i) anthropometry; (ii)analysis of dietary composition through a recall questionnaire; (iii) general medical records; (iv) blood samples for biochemical analysis and separation of plasma and DNA for freezing at $80^{\circ} \mathrm{C}$. In the plasma biochemical analysis of the first evaluation will be measured: glycated Hemoglobin, insulin, C-peptide, blood glucose, total cholesterol, triglycerides, HDL cholesterol, high-sensitivity C-reactive protein, urea, and creatinine. This study was approved by the ethics committee of the Federal District Secretariat of Health, and all patients enrolled signed an informed consent form authorizing the study.

\section{Brazilian Diabetes Study}

The BDS is a cohort formed between 2016 and 2018 with diabetic patients admitted after a campaign in print media, radio, and television. Thus, the population studied is composed of voluntary diabetic individuals assessed in the Clinical Research Center (CPC) of the State University of Campinas (Unicamp). The inclusion criteria were: (i) patients with type 2 diabetes mellitus (DM2), (ii) between 40 and 70 years old, (iii) absence of cognitive incompetence that prevents verbal response to medical questionnaires and the informed consent form. The exclusion criteria were: (i) patients diabetes mellitus phenotypes other than DM2; (ii) insulin-dependent individuals. In the first assessment, the study was explained in detail to the patients, and the informed consent form was presented. Then, the patients' identification and contact information were collected, followed by the medical history and a complete physical examination; the arterial pressure measured while seating and standing, the abdominal circumference, height, and weight were recorded. Finally, the patient's pharmacological characterization was recorded, and a diabetic polyneuropathy assessment conducted, in addition to data concerning the socioeconomic conditions and lifestyle. The research ethics committee of Unicamp approved the study, and all the patients signed the informed consent form in order to be enrolled in the study.

\section{Statistical analysis}

The quantitative data were presented as average +/- standard deviation. Comparison between the groups was carried out using the Student t-test for parametric continuous variables, the Mann-Whitey test for non-parametric continuous variables, and the $\chi 2$ test for continuous variables. The statistical analysis was performed using the SPSS version 20.0 (SPSS Inc., Chicago, Illinois, USA).

\section{RESULTS}

In the Brasília Heart Study, there were no statistically significant differences in demographic factors between the groups with the best and worst dyslipidemia control (age, years of formal education, sex, and body mass index). The average of formal education in the cohort was 7.32 of studying. As for the dyslipid- 
emia control, $21 \%$ of the patients reached LDL-C $<70$ (good), 32\% between 70-100 (intermediate) and 47\% > $100 \mathrm{mg} / \mathrm{dL}$ (inadequate).

As for the prevalence of comorbidities between the LDL-C groups, there was also no statistically significant difference between the prevalence of chronic liver disease and hypertension, and the average glycated hemoglobin in the groups with LDL-C $<70$, LDL-C $=70-100$, and LDL-C $>100 \mathrm{mg} / \mathrm{dL}$ was of $8.1(\mathrm{p}$ $=0.966)$, which suggests that the adequate control of LDL-Cis independent from the adequate control of blood glucose targets.

In the Brazilian Diabetes Study (BDS), there were also no statistically significant differences between the LDL-C groups in comparison with demographic factors. The is a non-significant tendency of a greater number of men in the LDL-C $<70(73.9 \%)$ group in comparison with the $70-100$ and $>100 \mathrm{mg} / \mathrm{dL}$ groups (55.6\% and 53.8\%, respectively; $p=0.058)$. Although the average formal schooling in this cohort (10.57 years of studying) is higher than in the BHS cohort, the dyslipidemia control was worse, with only $13 \%$ of patients reaching DL-C $<70$ (good), $21 \%$ between $70-$ 100 (intermediate), and 65\% > 100 (inadequate).

However, there are noteworthy statistically significant differences concerning comorbidities between the LDL-C groups. Concerning diabetes, there was a higher lack of blood glucose control in the group with a greater lack of dyslipidemia control. The average glycated hemoglobin is of 8.2 in the LDL-C $>100$ group in comparison with 7.7 and 7.5 in the 70-100 and $<70$ groups, respectively $(p=0.024)$. There is a higher percentage of hypertensive patients with LDL between $70-100(63.9 \%)$, when comparing the $<70$ and $>100$ groups ( $54.3 \%$ and $54.9 \%$, respectively; $p=0.005$ ). Diastolic pressure is higher in the group with LDL $>100$, with an average of $87 \mathrm{mmHg}$, in comparison with 82.6 mmHg and $81.9 \mathrm{mmHg}$ in the 70-100 and $<70$ groups, respectively $(p=0.019)$. The group with LDL $>100$ has the greatest percentage of smokers $(8.7 \%)$ in comparison with the groups with LDL between 70-100 and $<70$ (5.6\% and 4.3\%, respectively; $p=0.015)$. There is also a difference in the previous incidence of coronaropathy. In the group with LDL $<70,28.3 \%$ of patients had already experienced a previous infarction, compared with $11.1 \%$ and $10.6 \%$ in the $70-100$ and $>100$ groups, respectively ( $p<0.001)$. Thus, it is reasonable to conclude that chasing more aggressive targets of LDL-C is more frequent for diabetic patients in secondary prevention than to those on primary prevention.

\section{DISCUSSION}

Our work was one of the few in Brasil that proposed to evaluate the dyslipidemia control in diabetic populations. The results show that in both populations the control is beneath the desired (prevalence of adequate control of $32 \%$ in BHS and 13\% in BDS) and that the prevalence of dyslipidemia is high.

A similar study was Elsa, composed of public servants from six institutions of higher education and research in Brasil. The prevalence of diabetes, however, was of only $19.1 \%$, and the control with LDL $<70$ was reached in $2.5 \%$ patients. ${ }^{8}$ Another critical difference in this study is the level of formal education, with a greater prevalence of individuals with completed higher education. This suggests a higher socioeconomic level of the participants, with a likely prevalence of patients who already had medical follow-up by private or insurance medical professionals.

The difference in the prevalence of a previous coronaropathy found in the BDS can be explained by the secondary prevention since patients with a previous ischemic event usually have a more intense and rigorous control of dyslipidemia. ${ }^{9}$

Other findings of the BDS are compatible with previous results in the literature: the patients with worst dyslipidemia control have a higher incidence of smoking ${ }^{10}$ in this same population, present a higher diastolic pressure ${ }^{11-13}$ and, lastly, which is the purpose of the research, a worse blood glucose control was found in patients with higher levels of LDL $^{14,15}$.

In the Elsa study, it was found that the prevalence, awareness, and control of dyslipidemia were higher in men, black, and with less formal education. ${ }^{8}$ In the populations studied in our work, however, we found a higher dyslipidemia control in patients with lower levels of formal education. Again, the greater prevalence of patients with a higher socioeconomic level among the group with higher formal education might suggest a follow-up by private or insurance doctors. In this sense, the guidelines by the Brazilian Society of Endocrinology and Metabolism proposes to identify the cardiovascular risk for each patient, considering that each diabetic individual has a unique risk and, thus, rejecting the theory that everyone has a high cardiovascular risk. In contrast, the guidelines by the Brazilian Society of Cardiology (SBC) suggests strict targets for LDL-C, at $<70$ for everyone with high cardiovascu- 
lar risk - a group that includes diabetic individuals. This recommendation is based on studies that show a decrease in cardiovascular events in diabetic patients undergoing a strict control of lipids ${ }^{16-18}$.

As limitations, we can mention the small sample of patients in each of the cohorts used in our work in comparison with the Elsa study, for example. Besides, there were no statistically significant associations between the groups of patients of the BHS. Lastly, the inclusion criteria in the cohorts usually selects patients with specific profiles; thus, the data found are not representative of the general diabetic population in Brasil.

In conclusion, there are few data on the dyslipid- emia control in the Brazilian population, especially in people with diabetes. The data in our study shows that the control is inadequate and that there is a tendency of direct association between the lack of blood glucose control and the lack of dyslipidemia control, in addition to the association with other risk factors, such as diastolic hypertension and smoking. The limited control of dyslipidemia might be related to the plateau in the curve of mortality trend for diabetic individuals over the last decade. Inventing in the control of comorbidities, such as dyslipidemia, can potentially prolong survival and translate into improved cardiovascular health for diabetic individuals.

\section{RESUMO}

OBJETIVO: O diabetes é importante causa de mortalidade cardiovascular. Nos últimos anos, a mortalidade diminuiu substancialmente, mais em diabéticos do que em não diabéticos, em grande parte devido ao controle de outros fatores de risco cardiovasculares. Nosso estudo tem como objetivo analisar o controle de dislipidemia em duas coortes de diabéticos.

MÉTODOS: Foram estudados pacientes de duas coortes distintas, sendo 173 pacientes do BHS (Brasília Heart Study) e 222 pacientes do BDS (Brazilian Diabetes Study). Os dados sobre controle de dislipidemia foram estudados nas duas populações diferentes. Todos os pacientes eram diabéticos.

RESULTADOS: Há diferenças significativas em relação às comorbidades entre os grupos de LDL-C no BDS. A média de hemoglobina glicada é de 8,2 no grupo com LDL-C> 100, comparado com 7,7 e 7,5 nos grupos 70-100 e <70, respectivamente $(p=0,024)$. Há maior porcentagem de pacientes hipertensos com LDL entre 70-100 (63,9\%), quando comparado aos grupos < 70 e > 100 $(54,3 \%$ e 54,9\%, respectivamente; $p=0,005$ ). A pressão diastólica é mais elevada no grupo com $L D L>100$, com média de $87 \mathrm{mmHg}$, comparado com $82,6 \mathrm{~mm} \mathrm{Hg}$ e $81,9 \mathrm{mmHg}$ nos grupos $70-100$ e $<70$, respectivamente $(p=0,019)$. O grupo com LDL $>100$ tem maior porcentagem de tabagistas (8,7\%) quando comparado aos grupos com LDL entre 70-100 e < 70 (5,6\% e 4,3\%, respectivamente; $p=0,015)$. Há, também, diferença na incidência prévia de coronariopatia. No grupo com $L D L<70,28,3 \%$ dos pacientes já apresentaram infarto prévio, comparados com $11,1 \%$ e 10,6\% nos grupos 70-100 e > 100, respectivamente $(p<0,001)$.

CONCLUSÃo: Os dados do nosso estudo mostram que o controle de dislipidemia em diabéticos é inadequado, e há uma tendência de associação direta entre descontrole glicêmico e descontrole de dislipidemia, além de associação com outros fatores de risco cardiovascular, como hipertensão diastólica e tabagismo. Esse pior controle pode estar relacionado ao platô no descenso da curva de mortalidade, e o investimento nesse quesito pode melhorar a saúde cardiovascular dos diabéticos.

PALAVRAS-CHAVE: Dislipidemias. Diabetes mellitus. Fatores de risco. Metas.

\section{REFERENCES}

1. Arnold SV, Kosiborod M, Tang F, Zhao Z, McCollam PL, Birt |, et al. Changes in low-density lipoprotein cholesterol levels after discharge for acute myocardial infarction in a real-world patient population. Am J Epidemiol. 2014; 179(11): 1293-300.

2. Behradmanesh $S$, Nasri P. Serum cholesterol and LDL-C in association with level of diastolic blood pressure in type 2 diabetic patients. J Renal Inj Prev. 2012;1(1):23-6.

3. Bonaa KH, Thelle DS. Association between blood pressure and serum lipids in a population. The Tromso Study. Circulation. 1991;83(4):1305-14.

4. Cannon CP, Blazing MA, Giugliano RP, McCagg A, White JA, Theroux P, et al. Ezetimibe added to statin therapy after acute coronary syndromes. N Engl | Med. 2015;372(25):2387-97.

5. Chatterjee S, Khunti K, Davies MJ. Type 2 diabetes. Lancet. 2017;389(10085):2239-51.

6. Cholesterol Treatment Trialists' (CTT) Collaborators. Kearney PM, Black- well L, Collins R, Keech A, Simes |, Peto R, et al. Efficacy of cholesterol-lowering therapy in 18,686 people with diabetes in 14 randomised trials of statins: a meta-analysis. Lancet. 2008;371(9607):117-25.

7. Giugliano RP, Cannon CP, Blazing MA, Nicolau JC, Corbalán R, Špinar J, et al. Benefit of adding ezetimibe to statin therapy on cardiovascular outcomes and safety in patients with versus without diabetes mellitus: results from IMPROVE-IT (Improved Reduction of Outcomes: Vytorin Efficacy International Trial). Circulation. 2018;137(15):1571-82.

8. Gossett LK, Johnson HM, Piper ME, Fiore MC, Baker TB, Stein JH. Smoking intensity and lipoprotein abnormalities in active smokers. J Clin Lipidol. 2009;3(6):372-8.

9. Gregg EW, Cheng YJ, Saydah S, Cowie C, Garfield S, Geiss L, et al. Trends in death rates among U.S. adults with and without diabetes between 1997 and 2006. Diabetes Care. 2012;35(6):1252-7.

10. Klisic A, Kavaric N, Jovanovic M, Zvrko E, Skerovic V, Scepanovic A, et al. 
Association between unfavorable lipid profile and glycemic control in patients with type 2 diabetes mellitus. J Res Med Sci. 2017;22:122.

11. Lotufo PA, Santos RD, Figueiredo RM, Pereira AC, Mill JG, Alvim SM, et al. Prevalence, awareness, treatment, and control of high low-density lipoprotein cholesterol in Brazil: baseline of the Brazilian Longitudinal Study of Adult Health (ELSA-Brasil). J Clin Lipidol. 2016;10(3):568-76.

12. Mullugeta Y, Chawla R, Kebede T, Worku Y. Dyslipidemia associated with poor glycemic control in type 2 diabetes mellitus and the protective effect of metformin supplementation. Indian J Clin Biochem. 2012;27(4):363-9.

13. NCD Risk Factor Collaboration. Worldwide trends in diabetes since 1980: a pooled analysis of 751 population-based studies with 4.4 million participants. Lancet. 2016;387(10027):1513-30.

14. Faludi AA, Izar MCO, Saraiva JFK, Chacra APM, Bianco HT, Afiune A Neto, et al. Atualização da Diretriz Brasileira de Dislipidemias e Prevenção da Aterosclerose - 2017. Arq Bras Cardiol. 2017;109(2 Supl 1):1-76

15. Rawshani A, Rawshani A, Franzén S, Eliasson B, Svensson AM, Miftaraj M et al. Mortality and cardiovascular disease in type 1 and type 2 diabetes. $\mathrm{N}$ Engl | Med. 2017;376(15):1407-18.

16. Sabatine MS, Giugliano RP, Keech AC, Honarpour N, Wiviott SD, Murphy $\mathrm{SA}$, et al. Evolocumab and clinical outcomes in patients with cardiovascular disease. N Engl J Med. 2017;376(18):1713-22.

17. Sposito AC. Emerging insights into hypertension and dyslipidemia synergies. Euro Heart J. 2004;G8-G12.

18. World Health Organization. WHO diabetes country profiles 2016. [cited 2018 Jun 11]. Available from: http://www.who.int/diabetes/country-profiles/diabetes_profiles_explanatory_notes.pdf 